\title{
The Connotation, Theoretical Predicaments and Outlets of Eco-Feminism
}

\author{
Yonggang Zhao \\ School of Foreign Languages, China West Normal University \\ No. 1 Shi Da Road, Nanchong, 637009, Sichuan, China
}

\begin{abstract}
Eco-feminism has created an independent subject by the close combination of environmental history and women's history. Devoting to construct a polynary, holistic and correlated world view, eco-feminism will create a new relationship of shared symbiosis between human and nature, human and human, and human and the society. With the neoteric horizon and the huge influence, eco-feminism has had great importance theoretically and practically for it's impacts on the subjects like current western feminism, human philosophy, ethics, ecological environmental study and so on. However, eco-feminism has obvious drawbacks since some of its hypotheses deviate the objective reality. To make up the drawbacks, a feasible path is advocated by a newly ethical relation.
\end{abstract}

Keywords: Eco-feminism; connotation; predicaments; ethical perspective.

\section{INTRODUCTION}

Originating from 1970s, eco-feminism combined environmental history and women's history closely to each other. The concept of eco-feminism was rooted from the development of feminine revolution. In eco-feminism, the ideology of gender oppression can also be used in natural oppression in that there are some historical and social logical relations between them. Therefore it might be a better way to understand the phenomenon and solve the problem of the environment as well by bringing ecological crisis and woman's revolution together, taking both the oppression from men to women and the oppression of the nature into consideration positively, and demanding the revolution of not only women but also the nature. Devoting to a polynary, holistic and correlated world view, ecofeminism is trying to realize the new relationship between human and nature, human and human, and human and the society by criticizing the modern western philosophy. After decades of development, today's eco-feminism has had influence on the current western feminism, human philosophy, ethics, and ecological environmental study and so on. It has also attracted the attention of more and more scholars, and gradually become an independent subject. Nevertheless some of its assumptions which deviate from the reality give us the chance to ponder over in lots of aspects. It is of great significance to advocate a newly harmonious relation ethically which will provide a practical way for eco-feminism.

\section{The Connotation of ECo-Feminism}

The development of feminine revolution is influenced by the development of eco-feminism which advocates the achieving of equality between genders and proposes no hierarchy in the entire society. Eco-feminism also focuses deeply on natural environment protection, pursuing the harmonious coexistence between human and the nature. It issues the challenge against the current environmental ethics on the criticism and the reconstruction of relevant moral ideology. In spite of the assumptions deviating from the reality, eco-feminism deserves our rethinking. Its development which is all-around, for all people and highly comprehensive gets the views and thoughts from different academies together, creates an all-around value system, and is scientific and developmental. Eco-feminism discards the thoughts of male dominion formed in the past, highlights the sentimental values constantly, and regards it as a significant tool to facilitate the justice of the society. It is also theoretical and practical. 


\subsection{The Theoretical Connotation of Eco-Feminism}

Eco-feminism is of great importance and value in the development of ecological ethics and feminism. Even though eco-feminism originated from women's revolution and the environmental revolution, it doesn't mean it's about environment protection, nor feminism, or the incondite combination of both. Instead, it is a part of both feminism and ecological ethics. It makes up the knowledge in history, philosophy and politics between them, which makes it a vigorous ontology and a new way of thinking. The most important reason why ecologism and feminism can combine with each other is that they are both against anthropocentrism and male chauvinism.

First of all, eco-feminism expanded the perspective of environmental ethics and feminism. On the one hand, the attitude of the human to the nature experienced a change from anthropocentrism to nonanthropocentrism in the environmental ethics of 20th century. However, both of the perspectives encountered lots of challenges, such as the destruction of ecological environment and its harmful influence on human beings, and the way how people solve the conflicts and keep the promise for the nature. Faced with diverged predicaments of anthropocentrism and non-anthropocentrism, ecological philosophers advocated a substitution for "environment coordination", saying that the main ideas is that there is a synergy between the respect for the nature and human. On the whole, the respect from human to nature and that of the nature to human will bring benefits to each other in the long run. In terms of the modulation of centralism or the non-centralism in anthropocentrism and non-anthro pocentrism, environment coordination has clearly changed. It is no longer a conflict between human beings or between human and the nature, but a harmony of mutualism and common achievement. Eco-feminism is part of the environment coordination, and clams that human's respect to the nature can enhance our own welfare, and, at the meantime, the respect to all human beings can also protect the nature as well. On the other hand, from feminism to eco-feminism, the scholars do not take the perspective only from gender or ecology. Instead, they do the study on the perspective against women discrimination, ecology discrimination and oppression. They turn the perspective from the pursuit of female status and rights to the combination with ecology protection, and re-estimate women's status and function from the perspective of socialized mass production, finally, examine the relationship between itself and the environment and environment-protection, which makes great progress. Therefore, it provides humans a new horizon to handle the relationship between humans and the nature and perfects the traditional feminism and ecological ethics from a new and all-around perspective on the whole universe.

Furthermore, it criticized the unenlightened ideology. Eco-feminism criticized many aspects. It criticized the world view and dualism of patriarchy, claming that patriarchy is the root of gender oppression and ecological crisis. So it puts that the most initial step for the problem solving in ecological crisis and gender justice is to overthrow the culture of patriarchy thoroughly. Eco-feminism criticized modern mechanical conception of nature, which was considered having changed the harmonious relationship between human beings and nature, ascertaining the infinite governing, and leading to the deterioration of natural environment and its revenge to human beings. Meanwhile the mechanical conception of nature regards male people, the so called rational creatures, as main part of the society, while the female, same as the nature, the ones whom governed by the male, worsening the inequality between genders. Eco-feminism criticized scientific development, opposing that science is the only effective way to acquaint the world. It held that scientific revolution is inherited the view in mechanical conception of nature that, "Human is the most powerful law maker," and considered it anti-natural, claming that it ignored human's dependence on nature, on the country, classified creatures by technology. Finally, it puts the human beings themselves at the top or in the central place. Similarly, when it comes to the world of human beings, it is the domination of men and the being governed of women. Eco-feminism comments fiercely on racism and militarism as well. It has always been in the beliefs of peace, justice and care, demands the collapse of all types of exploitation and oppression, and takes practical actions to the policy of military and nuclear weapons. In fact, all the beliefs of eco-feminism are going the opposite way of racism and militarism.

\subsection{The Practical Significance of Eco-Feminism}

Encountering the precarious ecological environment and the unfair notion of gender, eco-feminism has become stronger and stronger constantly from history digging to reality focusing and from experience summarizing to theory completing. Eco-feminism has become a civilian political 
campaign due to its theoretical comments on the unenlightened feudal thoughts like patriarchy and its focus on practical effects. Firstly, it symbolizes another highlight in feminism; secondly, it also marks the new stage of environmental protection movement. Its main phenomena are as the following:

Firstly, it shows the practical connotation for ecological environmental protection. Because woman's destiny is always closely linked to environmental problems, the two have much in common on earth. The deterioration of environment is the main factor influencing the quality of women's existence and life style. Thus eco-feminism pays close attention to environment protection, and will be an urgent pioneer to revolt environmental unfairness. Since 1970, the climax of revolution for racial opposition and poverty elimination has emerged one after another globally, highlighting the environmental fairness in front of the international community. Actively involved in those campaigns, advocators of eco-feminism focus on the dependent relationship on each other among individuals, the society and nature, and affirm the inner values of all the creatures in the world instead of man's excessive control and exploitation on nature. They firmly believe that humans should respect nature to change the status of women and nature by removing the mechanism of male chauvinism, then the ultimate goal will be achieve - the fairness of women's status will be safeguarded and facilitated.

Secondly, it has practical significance in the achievement of gender fairness of the society. After thirty years' development, as the third representative of feminism, eco-feminism has had plenty of contribution to gender fairness, and has made huge differences in the western feminism theoretically and practically. It focuses on women's living environment, the promotion of women's social status in undeveloped districts, and women's health, safety, rights and interests. Eco-feminism has clarified the direction of the development of gender relationship, focuses on gender equality, and criticizes the binary opposition between men and women. It advocates the interdependence, coexistence and mutual assistance between genders, and claims that only by equal dialogues and the gradually formed healthy environment of cooperation and communication, can there be the harmony between genders.

Thirdly, it's meaningful for the construction of a harmonious society. Beginning with the connection between the oppression of women and the nature, eco-feminism has not only challenged sexism and patriarchy, but also threatened anthropocentrism, which insults the value and dignity of the nature. Further, it hangs out the red flag to every modality of governing, thus provides a reference for the construction of a harmonious society. Eco-feminism has safeguarded one of the primary interpersonal relationships by the struggle in patriarchy and sexism--the harmony between men and women. Focusing on the status of women, it attaches importance to women's function and value in the society. It puts emphasis on the equality, the joint development and the mutual promotion between men and women, and advocates that the love, caring and understanding for the view of values will drive other sides of the society, like the nationality, stratum and group, in a fine direction.

\section{The Predicament of Eco-Feminism}

In theory and in practice, eco-feminism goes with positive meanings. It takes a new perspective to look at the world, and injects fresh vitality for the development of feminism and ecology. However, as a non-conventional theory, in the process of theory construction and practice eco-feminism has encountered difficulties or doubts.

\subsection{The Paradoxes of Feminism and Ecology}

Surpassing the study that traditional feminism focused on the gender problem, eco-feminism discusses relationships among varied persons and groups, and expands its focus to the relationship between human and nature. Its logical starting point is the analogy of the relationship between genders in human beings and between human and nature, opposing male centrality and anthropocentrism, to initiate a theoretical cultural liberation for the overturn against the binary rule policy. Compared with the relationship between men and nature, eco-feminism believes that women are closer to the nature, which has been in criticism by other schools.

Firstly, the basic perspective of women is originated from the division between the perspective of men and women. However, that kind of division is based on the belief that either men or women belong to human beings, which includes both the perspectives of men and women. Feminism is celebrated for its emphasis on the difference between men and women, and tends to highlight the vulnerable groups, women themselves, and their promised traits, to get women's liberation by the upholding of women's 
rights. In brief, feminism is a theoretical perspective for women liberation by the logical criticism of the strong and the weak based on the division of genders, while eco-feminism is a global perspective focusing on the concept of nature. Nature represents all existence in true ecological perspective. Things are not independent from each other, in which human is a part or a node of nature, which shows that the relationship between human and nature is not like so isolating, but human's unconditional subordination to nature. Therefore, there must be a dependent and integral relationship between human and nature. As a result, there must be arguments and criticism while getting feminism and ecology together to be eco-feminism. Furthermore, eco-feminism regards the form of dualistic governing in patriarchy as the common basis of human's plunder from the nature and the oppression from men to women. For example, the connections between women and nature don's coincide in different space-time. Due to the low level of productivity, human beings were in full control of nature in ancient times, which made themselves the slavers of nature. Thus the female figure of "earth mother" tells human's reverence to the nature. With the development of technology and the improvement of productivity, non-human nature becomes the object for understanding and transformation. The thought of the diversity between the subject and the object is gradually presented as the opposition between them. Along with the modern industrial civilization, the female image of a mother pays due attention to the family and affection, and retreats in the public life, sense and emotion, mind and nature, objectivity and subjectivity, public and private, work and family are seen from separation to opposition, demonstrating a rank of priority and inferiority.

\subsection{The Theoretical Predicament of Eco-Feminism}

The theoretical predicament of eco-feminism is found in two aspects.

First, the difficulties caused by the construction of a diversified ideological system. Eco-feminism is strongly inclusive and open. It is not only the integration of feminist theory and ecological theory, but also a diversified ideological system. It aims to integrate diverse theories and enrich its own theory system with flexibility and diversity. But obviously it is very difficult to establish a theoretical system with both universality and objectivity. Second, as the foregoing illustration, eco-feminism is conducted to probe into the connection between male centralism and human centralism. It attempts to resolve the two problems in mutual promotion. Whereas, the diversities between nature and female are overt, the practice brings about questions as to what extent nature and female could in analogy. Meanwhile, when we tackle the conflicts of men and nature, usually respect for nature is advocated. An analysis of the interests between men and nature, the relationship between the part and the whole may evoke sympathies from men. But the point is with the same approach whether we could realize the emancipation of women, or eliminate the inequality between sexes. Similarly, even if feminism truly realizes the emancipation of women by way of breaking the hierarchic model based on dualism and patriarchy, how could it be applied to the liberation of nature? Or when women are emancipated and freedom and right are ensured, could the situation in nature be improved? Obviously, the theoretical construction of eco-feminism and its own meaning are facing many challenges.

\section{The Ethical Perspective of Getting Rid of the Predicament}

From what has been mentioned above, the theoretical predicament of eco-feminism in fact is dualism. Whereas dualism is not to affirm diversity, nor does it ranks the two parties, but to extremalize and absolutize diversities, which leads to the rationalization of the dominance relation. Therefore, to get rid of the theoretical predicament, a value system is required to deconstruct the extreme distinction and dominant relation of dualism, the aim of which is to reconstruct a none-dualism ethic with the concept of none-hierarchical difference. Some learners hold that caring ethic is one of nonehierarchical difference. The reason comes that caring ethic is new and none-dualistic. Its marked characteristics are: first, it proposes to break the antagonistic relationship between self and the other to construct mutual relation. Second, it emphasizes emotive factors' importance in ethic acts. Third, it stresses to intensify caring behaviors under specific circumstances. In the perspective of caring ethic, male and female, human beings and nature are in harmonious relation based on relevance, relationship, concerns and responsibility. On the one hand, it abandons the old idea of an absolute opposition between male and female, men and nature. Instead, it admits that they are in a relation of inter-dependence. Such relation is a reciprocal relation between caring and being cared, and an interdependent one. On the other hand, it lays emphasis on the function of emotive factors in ethic judgments and cognition. None-rational factors such as cares, sympathies and emotions could 
improve the unconcerned relation between male and female, men and nature. On the matter of male and female, men and nature, caring ethic stands not on dualism, nor does it ignore the differences between them. Instead, it sees men and nature in an inter-dependent relation, male and female in a mutually caring and connected relation. In this sense, sympathies, concerns and other emotive factors could serve to coordinate their relationships.

\section{REFERENCES}

[1] Heather Eaton. Introducing Ecofeminist Theologies [M] New York: $\mathrm{T} \& \mathrm{~T}$ Clark International, 2005: 12 .

[2] Karen.J.Warren. Ecofeminist Philosophy: A western pespectives on what it is and why it matters [M]. rowman and Litterfield Publishers,2000.63

[3] Michael E. Zimmerman. Contesting Earth's Future: Radical Ecology and Postmodernity [M] Berkeley: University of California Press, 1994: 233.

[4] S.Glendon. Sexual Politics and Political Feminism [M].JA I Press Inc.1991.223-235.

[5] Val Plumwood. Feminism and the Mastery of Nature [M]. New York: Routledge.1993.5

\section{AUTHOR's BIOGRAPHY}

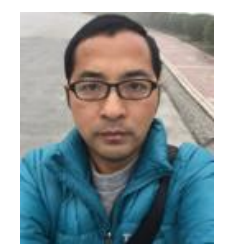

Zhao Yonggang, Ph. D., a associate professor at the College of Foreign Language, Chinawest Normal University (Nanchong, 637009). His major research interest is Anglo-American literature. Email: zhyg007@163.com. 